\title{
IMPROVEMENT OF A THERMOELECTRIC AND VAPOUR COMPRESSION HYBRID REFRIGERATOR
}

\author{
D. Astrain, A. Martínez, A. Rodríguez \\ Mechanical, Energy and Materials Engineering Department \\ Public University of Navarre, 31006 Pamplona, Spain \\ Tel: +34 948 169597, Fax: +34948 169099, e-mail: david.astrain@unavarra.es
}

\begin{abstract}
This paper presents the improvement in the performance of a domestic hybrid refrigerator that combines vapour compression technology for the cooler and freezer compartments, and thermoelectric technology for a new compartment. The heat emitted by the Peltier modules is discharged into the freezer compartment, forming a cascade refrigeration system. This configuration leads to a significant improvement in the coefficient of operation. Thus, the electric power consumption of the modules and the refrigerator decrease by $95 \%$ and $20 \%$ respectively, with respect to those attained with a cascade refrigeration system connected with the cooler compartment.

The optimization process is based on a computational model that simulates the behaviour of the whole refrigerator. Two prototypes have been built and tested. Experimental results indicate that the temperature of the new compartment is easily set up at any value between 0 and $-4{ }^{\circ} \mathrm{C}$, the oscillation of this temperature is always lower than $0.4{ }^{\circ} \mathrm{C}$, and the electric power consumption is low enough to include this hybrid refrigerator into energy efficiency class A, according European rules and regulations.
\end{abstract}

Keywords: Thermoelectrics, Computational model, Refrigeration, Vapour compression, Thermal resistance, Coefficient of operation

\section{NOMENCLATURE}

$\begin{array}{lll}C & \text { Thermal capacity } & \mathrm{J} / \mathrm{K} \\ c_{p} & \text { Specific heat at constant pressure } & \mathrm{J} / \mathrm{kgK} \\ E & \text { Seebeck thermoelectric force } & \mathrm{V} \\ e & \text { Wall thickness } & \mathrm{m} \\ e_{\text {te-freez }} & \text { Thickness of the wall between thermoelectric and freezer compartments } & m \\ h_{\text {ext }} & \text { External convection heat transfer coefficient } & \mathrm{W} / \mathrm{m}^{2} K \\ h_{\text {int }} & \text { Internal convection heat transfer coefficient } & \mathrm{W} / \mathrm{m}^{2} K \\ I & \text { Electric current } & \mathrm{A} \\ J & \text { Electric current density } & \mathrm{A} / \mathrm{m}^{2}\end{array}$


$\mathrm{Nu} \quad$ Nusselt number

Pr Prandtl number

$\dot{Q} \quad$ Heat flow rate $\quad W$

$\dot{Q}_{\text {cool }} \quad$ Cooling power $\quad W$

$\dot{Q}_{\text {freez }} \quad$ Freezing power $W$

$\dot{Q}_{P} \quad$ Heat flow rate due to Peltier effect W

$\dot{Q}_{p, c} \quad$ Heat flow rate absorbed at the cold end of the modules W

$\dot{Q}_{p, h} \quad$ Heat flow rate generated at the hot end of the modules $\quad W$

$\dot{q} \quad$ Specific heat flow rate generated $\quad \mathrm{W} / \mathrm{m}^{3}$

$\dot{q}_{J} \quad$ Specific heat flow rate due to Joule effect $\quad \mathrm{W} / \mathrm{m}^{3}$

$\dot{q}_{p, c} \quad$ Heat flux absorbed at the cold end of the modules $\quad \mathrm{W} / \mathrm{m}^{2}$

$R \quad$ Thermal resistance $\quad K / W$

$R_{d c} \quad$ Cold side heat exchanger thermal resistance $\quad K / W$

$R_{d h} \quad H o t$ side heat exchanger thermal resistance $\quad K / W$

Re Reynolds number

S Surface area $\quad m^{2}$

$S_{p} \quad$ Total surface area of the Peltier modules $\mathrm{m}^{2}$

T Temperature $\quad K$

T' Temperature at instant of time $\tau+\delta \tau \quad K$

$\begin{array}{lll}T_{a} \quad \text { Ambient temperature } & K\end{array}$

$T_{\text {cext }} \quad$ Temperature of the cold extender $\quad K$

$T_{\text {cool }} \quad$ Temperature in the cooler compartment $\quad K$

$T_{\text {freez }} \quad$ Temperature in the freezer compartment $\quad K$

$T_{p, c} \quad$ Temperature at the cold end of a Peltier module $\quad K$

$T_{p, h} \quad$ Temperature at the hot end of a Peltier module $\quad K$

$T_{\text {te }} \quad$ Temperature in the thermoelectric compartment $\quad K$

$\begin{array}{ll}U & \mathrm{Weat} \text { transfer coefficient } \\ \mathrm{W} / \mathrm{m}^{2} \mathrm{~K}\end{array}$ 


$\begin{array}{lll}V_{\text {te }} & \text { Voltage supplied to the Peltier modules } & \mathrm{V} \\ V & \text { Volume } & \mathrm{m}^{3} \\ \dot{W}_{\text {cool }} & \text { Electric power consumption of the cooler } & \mathrm{W} \\ \dot{W}_{\text {freez }} & \text { Electric power consumption of the freezer } & W \\ \dot{W}_{\text {te }} & \text { Electric power consumption of the thermoelectric device } & \mathrm{W} \\ \dot{W}_{\text {tot }} & \text { Electric power consumption of the hybrid refrigerator } & \mathrm{W} \\ Z & \text { Figure of merit } & 1 / \mathrm{K} \\ \Delta T_{\text {cool }} & \text { Temperature oscillation in the cooler compartment } & \mathrm{K} \\ \Delta T_{\text {freez }} & \text { Temperature oscillation in the freezer compartment } & \mathrm{K} \\ \Delta T_{\text {te }} & \text { Temperature oscillation in the thermoelectric compartment } & \mathrm{K} \\ \alpha & \text { Seebeck coefficient } & \mathrm{V} / \mathrm{K} \\ \rho & \text { Electrical resistivity } & \mathrm{Ohm} \times \mathrm{m} \\ \tau & \text { Time } & \mathrm{s} \\ \delta & \text { Density } & \mathrm{kg} / \mathrm{m}^{3} \\ \pi & \text { Peltier coefficient } & \mathrm{V}\end{array}$

\section{INTRODUCTION}

The thermoelectric effects, namely, Joule, Seebeck, Peltier and Thomson, describe the interaction between thermal and electric fields, and are well known since the XIX century [1]. Back in 1885, John W. Strutt raised the possibility of using thermoelectric devices to produce electric power, though further developments were rejected because of the low efficiencies attained. The major breakthrough did not take place until the application of semiconductor materials to thermoelectric devices by Abram F. Ioffe in 1957 [2]. These materials feature high Seebeck coefficient, low electrical resistivity and low thermal conductivity, which entails high Figure of merit $\left(Z=\alpha^{2} / \rho k\right)$, key parameter in 
the characterization of thermoelectric materials. Ioffe's development led to successful thermoelectric heating and cooling applications for military and aerospace purposes $[3,4]$.

Nowadays, thermoelectric technology is making its way into the civil market, especially for applications that require high quality temperature control, such as precision instruments for medicine and research [5, 6]. Moreover, several thermoelectric applications are attracting commercial attention owing to their great prospects for the future, such as dehumidifiers [7], air conditioners for domestic and automotive sectors, portable and domestic refrigerators, transports for perishable goods, etc, which compete with vapourcompression based applications [8].

Thermoelectric refrigeration offers several advantages with respect to conventional vapour compression technology, since thermoelectric devices are more compact, free of noises and vibrations, provide high quality temperature control and require far less maintenance [9-11]. These significant facts led to the development of original and interesting thermoelectric refrigeration devices, subsequently released into the market [12$15]$.

Coefficient of operation (COP) of thermoelectric refrigerators, on the other hand, is significantly lower than that of vapour-compression based devices, which explains the fact that vapour compression technology predominates in both industrial and domestic refrigeration markets. However, one of the main disadvantages of vapour-compression based refrigerators lies on the oscillatory pattern of the inner temperature, caused by the characteristic stop and start cycles of the compressor. This effect leads to very significant oscillations in the temperature of the air enclosed in the refrigeration compartment, which worsens to a great extent the conservation of food or perishable goods [16].

Scientific literature shows some systems intended to reduce the cited temperature oscillation of vapour compression refrigerators, using either variable speed compressors $[17,18]$, fixed speed compressors with improved temperature control systems $[19,20]$ or 
new components such as thermostatic expansion valves, which regulate the mass flow of the cooling fluid [21, 22]. However, these systems turn out to be excessively complex and expensive for being installed in commercial domestic refrigerators, given the competitiveness of the market, which explains the fact that manufacturers prefer cheaper and simpler devices, such as capillary tubes, which finally entails a decrease in the quality of the temperature control. Thermoelectric technology, appropriately designed and applied, outstands as a promising alternative to attain accurate temperature control systems for domestic refrigerators.

In line with current research in thermoelectric applications for domestic refrigeration, a previous paper [23] introduced a domestic thermoelectric refrigerator which included two phase-change thermosyphons attached to either end of the thermoelectric modules. These devices enhanced the heat transfer and increased the COP of the refrigerator by $60 \%$, yielding 0.4 (still far lower than COP of vapour compression refrigerators, usually higher than 1). This significant improvement, along with the cited advantages of thermoelectric refrigerators, led to the design of a hybrid refrigerator that combined thermoelectric and vapour compression technologies [24]. One prototype was built, which comprised three compartments: freezer and cooler compartments refrigerated with vapour compression technology, and a new compartment refrigerated with thermoelectric technology. The temperature of this thermoelectric compartment kept steady at $0{ }^{\circ} \mathrm{C}$ with an oscillation lower than $\pm 0.5^{\circ} \mathrm{C}$. The heat flow rate emitted by the thermoelectric modules was given off into the cooler compartment. The electric consumption of the refrigerator was $1.15 \mathrm{kWh} /$ day $(48.1 \mathrm{~W})$, so it was ranked B among energy efficiency classes.

This paper continues that work and presents an improvement of this hybrid domestic refrigerator. 


\section{OBJECTIVES}

The main objective of this work is to improve a hybrid domestic refrigerator that combines vapour compression and thermoelectric technologies. In order to accomplish this aim, the following specific objectives are proposed:

- To develop a computational model that simulates the behaviour of the whole hybrid refrigerator.

- To develop and construct a hybrid domestic refrigerator with three compartments, one of them refrigerated with thermoelectric technology. The inner temperature of this thermoelectric compartment must be set up at any value between 0 and $-4{ }^{\circ} \mathrm{C}$, and oscillate within $\pm 0.2^{\circ} \mathrm{C}$, thus enhancing the conservation quality.

- To improve the main components of the thermoelectric system in order to reduce the electric power consumption of the refrigerator, with respect to that of a previous thermoelectric refrigerator [24] (energy efficiency class B), so that it could be included in energy efficiency class A.

\section{DESCRIPTION AND THEORETICAL PERFORMANCE OF THE HYBRID}

\section{REFRIGERATOR}

The concept of thermoelectric-vapour-compression hybrid refrigeration lies on the idea of combining the high COP provided by vapour compression technology and the high quality temperature control attainable with thermoelectric devices. The hybrid refrigerator is composed of three compartments, as can be seen in Figure 1:

- Cooler compartment, which is refrigerated with vapour compression technology. The temperature in this compartment ranges from 8 to $2{ }^{\circ} \mathrm{C}$.

- Freezer compartment, refrigerated also with vapour compression technology. Temperatures ranging from -28 to $-15^{\circ} \mathrm{C}$.

- Thermoelectric compartment, refrigerated with thermoelectric technology. The 
temperature ranges from 0 to $-4^{\circ} \mathrm{C}$.

Thermoelectric refrigeration is based on the Peltier effect [1], which explains the cooling or heating that occurs when an electric current flows through the joint of two dissimilar materials (the so-called thermoelectric pair). The heat flow generated or absorbed by Peltier effect depends on the temperature in the joint and the materials' properties. Several thermoelectric pairs connected electrically in series and thermally in parallel compose a Peltier module, whose performance is determined by Seebeck, Peltier, Joule, Thomson and Fourier effects.

A thermoelectric device comprises one or several Peltier modules and a heat exchanger attached to either side of them. As was previously proved [25, 26], COP of a Peltier module depends to a great extent on the temperature at either end of it. Moreover, it is essential to dissipate properly the heat flow rate at the hot end, and maintain the module as cold as possible.

In the development of the hybrid refrigerator, there were considered three different configurations for the thermoelectric device, as Figure 1 presents.

\subsection{Configuration I}

In this configuration, the Peltier modules are placed in the rear wall of the thermoelectric compartment, and when supplied with an electric power, they absorb heat from this compartment and emit heat directly to the environment. The thermoelectric device is composed of the Peltier modules; a cold side heat exchanger, which connects the cold end of the modules to the air inside the thermoelectric compartment; a hot side heat exchanger, which evacuates heat form the hot end of the modules; and a cold extender, installed to connect the cold side heat exchanger to the modules. This device meets the first law of thermodynamics, therefore the heat flow rate absorbed at the cold end plus the electric power supplied to the modules equals the heat flow rate given off at the hot side, as 
Eq. (1) points out.

$$
\dot{Q}_{p, h}=\dot{Q}_{p, c}+\dot{W}_{t e}
$$

This configuration has the inconvenience that, as the heat from the hot end of the Peltier modules is given off directly into the environment, the temperature difference between ends of the modules is significantly high (in fact, higher than $30^{\circ} \mathrm{C}$ ). Then, the COP of the thermoelectric device is very low, as can be deduced from Eq. (2) [1].

$$
\begin{aligned}
& C O P=\frac{\dot{Q_{p, c}}}{\dot{W}_{t e}}=\left[\frac{T_{p, c}}{T_{p, h}-T_{p, c}}\right]\left[\frac{m_{o p t}-\frac{T_{p, h}}{T_{p, c}}}{m_{o p t}+1}\right]=C O P_{\text {Carnot }} C O P_{\text {relative }} \\
& m_{\text {opt }}=\sqrt{1+Z \frac{T_{p, h}+T_{p, c}}{2}}
\end{aligned}
$$

\subsection{Configuration II}

In order to decrease the temperature difference between the ends of the Peltier modules, the thermoelectric device is placed in the wall between the cooler compartment and the thermoelectric compartment, as Figure 1 shows. Then, the heat from the hot side of the Peltier modules is emitted into the cooler compartment, absorbed by the evaporator and given off to the environment by the vapour compression system, with COP close to 1 . This forms a cascade refrigeration system combining thermoelectric and vapour compression technologies. The required power of the cooler compartment increases in this configuration II with respect to that in configuration I, as Eq. (3) indicates.

$$
\dot{Q}_{\text {cool }}^{\prime}=\dot{Q}_{\text {cool }}+\dot{Q}_{p, h}=\dot{Q}_{c o o l}+\dot{Q}_{p, c}+\dot{W}_{t e}
$$

The advantage of configuration II is that the temperature difference between ends of the Peltier modules decreases, since the heat exchanger of the hot side connects the modules to an environment at about $5{ }^{\circ} \mathrm{C}$, which entails an increase in the $\mathrm{COP}$, as shown 
in subsequent sections.

\subsection{Configuration III}

Following the idea of decreasing the temperature of the hot end of the Peltier modules and therefore reduce the temperature difference between their ends, we designed configuration III, characterized by the fact that the thermoelectric device was installed in the wall between the freezer and thermoelectric compartments, as Figure 1 displays. In this configuration, the heat from the hot side of the Peltier modules is emitted directly into the freezer compartment, where is absorbed and given off to the environment, so that the required power of the freezer compartment increases according to Eq. (4)

$$
\dot{Q}_{\text {freez }}^{\prime}=\dot{Q}_{\text {freez }}+\dot{Q}_{p, h}=\dot{Q}_{\text {freez }}+\dot{Q}_{p, c}+\dot{W}_{\text {te }}
$$

Therefore, configuration III is also a cascade refrigeration system with the great advantage that the Peltier modules work in optimal conditions, since their hot ends are connected to an environment at extremely low temperatures (below $-22{ }^{\circ} \mathrm{C}$ ), thus increasing the $\mathrm{COP}$ and reducing the electric power consumption of the thermoelectric device.

\section{DESIGN AND FURTHER IMPROVEMENT OF THE NEW HYBRID}

\section{REFRIGERATOR}

In order to design and propose some improvements of the hybrid refrigerator, the following methodology is conducted:

- Implementation of a computational model to simulate the whole hybrid refrigerator and study of the influence of different parameters, such as number of Peltier modules installed, position of the thermoelectric device, thermal resistances of the heat exchangers, thickness of the walls, etc. This model is intended to determine the best option between configurations I, II and III, and quantify the differences between them. The heat 
exchangers at either side of the Peltier modules are studied with Computational Fluid Dynamics software (CFD), in order to reduce their thermal resistance.

- Improvement of the hybrid refrigerator based on experimental tests conducted with prototypes.

\subsection{Computational model}

The computational model solves the set of equations composed of the thermoelectric effects, namely Seebeck, Peltier and Joule, and the transient heat conduction, represented by Eqs. (5) to (8) respectively.

$$
\begin{aligned}
& \alpha=\frac{d E}{d T}=\alpha_{\text {materialA }}-\alpha_{\text {materialB }} \\
& \dot{Q}_{P}= \pm \pi I= \pm I T\left(\alpha_{\text {materialB }}-\alpha_{\text {materialA }}\right) \\
& \dot{q}_{J}=\frac{J^{2}}{\rho} \\
& c_{p} \delta \frac{\partial T}{\partial \tau}=\nabla(k \nabla T)+\dot{q}
\end{aligned}
$$

The following hypotheses are taken into account:

- Materials are isotropic.

- Thomson effect has insignificant influence compared to that of Peltier and Joule effects $[1]$.

The model is implemented in MatLab and is based on the implicit finite difference method [27]. The inputs of the model are: dimensions and thermal properties of the compartments, type of Peltier modules (dimensions and materials), voltage supplied to the modules, thermal resistance of the heat exchanger at either side of the modules, and cooling and freezing average power in cooler and freezer compartments respectively. The outputs are: temperatures of all the elements and compartments as a function of time, heat 
flow rates, electric power consumption and $\mathrm{COP}$ of both the thermoelectric device and the refrigerator.

The finite difference method requires the discretization of the system, which consists in reducing the system into a set of representative nodes. Figures 2, 3 and 4 present the discretization of the hybrid refrigerator for configuration I, II and III respectively. Every node has a thermal capacity provided by Eq. (9), and is connected to the surrounding nodes by thermal resistances calculated with Eq. (10).

$$
\begin{aligned}
& C=V \delta c_{p} \\
& R=\frac{L}{k S}
\end{aligned}
$$

The thermal resistances corresponding to the walls of the refrigerator, where both heat transfer conduction and convection take place, can be calculated with Eq. (11), where the heat transfer coefficient is obtained with Eq. (12).

$$
\begin{aligned}
& R_{\text {wall }}=\frac{1}{U S} \\
& U=\frac{1}{\frac{1}{h_{\mathrm{int}}}+\frac{e}{k}+\frac{1}{h_{\text {ext }}}}
\end{aligned}
$$

The convection coefficient inside and outside every compartment $\left(h_{\text {int }}, h_{\text {ext }}\right)$ is calculated with Eq. (13), which is an experimental expression of the convection coefficient in a plane plate that considers laminar flow and dismisses the influence of the viscosity dissipation [28].

$$
\begin{aligned}
& N u_{L}=0.664 \operatorname{Pr}^{1 / 3} \operatorname{Re}_{L}{ }^{1 / 2} \\
& {\left[\begin{array}{l}
0.6 \leq \operatorname{Pr} \leq 50 \\
\operatorname{Re}<\operatorname{Re}_{x, c} \approx 5 \times 10^{5}
\end{array}\right]}
\end{aligned}
$$

The thermal contact resistance between a common $40 \times 40 \mathrm{~mm}^{2}$ Peltier module and the cold extender yields $0.03 \mathrm{~K} / \mathrm{W}$ [29]. 
The nodes representing the Peltier module also include heat absorption or generation corresponding to Peltier and Joule effects, presented by Eqs. (6) and (7). As an example, Eqs. from (14) and (17) present the energy balance corresponding to node 6 in Figure 3, which represents a node of the Peltier modules, where $\dot{Q}_{6}$ stands for a ninth of the heat generated by Joule effect provided by Eq. (7), $C_{6}$ is the thermal capacity of node 6 obtained with Eq. (9), $R_{56}$ and $R_{67}$ stand for the thermal resistances between nodes 5-6 and 6-7 respectively, obtained with expression (10). Finally, $T_{6}$ and $T_{7}$ represent the temperatures of nodes 6 and 7 in the instant of time $\tau$, whereas $T^{\prime}{ }_{5}, T^{\prime}{ }_{6}$ and $T_{7}^{\prime} 7$ represent the temperatures of nodes 5,6 and 7 in the instant of time $\tau+\delta \tau$.

$$
\begin{aligned}
& \frac{T_{5}^{\prime}-T_{6}^{\prime}}{R_{56}}+\frac{T_{7}^{\prime}-T_{6}^{\prime}}{R_{67}}+\dot{Q}_{6}=\frac{C_{6}}{\delta \tau}\left(T_{6}^{\prime}-T_{6}\right) \\
& -\frac{T_{5}^{\prime}}{R_{56}}-\frac{T_{7}^{\prime}}{R_{67}}+\left(\frac{1}{R_{56}}+\frac{1}{R_{67}}+\frac{C_{6}}{\delta \tau}\right) T_{6}^{\prime}=\frac{C_{6}}{\delta \tau} T_{6}+\dot{Q}_{6} \\
& -\frac{\delta \tau}{C_{6}} \frac{1}{R_{56}} T_{5}^{\prime}-\frac{\delta \tau}{C_{6}} \frac{1}{R_{67}} T_{7}^{\prime}+\frac{\delta \tau}{C_{6}}\left(\frac{1}{R_{56}}+\frac{1}{R_{67}}+\frac{C_{6}}{\delta \tau}\right) T_{6}^{\prime}=T_{6}+\frac{\delta \tau}{C_{6}} \dot{Q}_{6} \\
& -\frac{\delta \tau}{C_{6}} \frac{1}{R_{56}} T_{5}^{\prime}+\left[\frac{\delta \tau}{C_{6}}\left(\frac{1}{R_{56}}+\frac{1}{R_{67}}\right)+1\right] T_{6}^{\prime}-\frac{\delta \tau}{C_{6}} \frac{1}{R_{67}} T_{7}^{\prime}=T_{6}+\frac{\delta \tau}{C_{6}} \dot{Q}_{6}
\end{aligned}
$$

Likewise, Eqs. from (18) and (21) shows the energy balance for node 4 also in Figure 3, which corresponds to the hot end of a Peltier module, where $\dot{Q}_{4}$ represents a ninth of the heat generated by Joule effect plus the heat absorbed by Peltier effect provided by Eq. (6), $C_{4}$ is the thermal capacity of node 4 obtained with Eq. (9), $R_{34}$ y $R_{45}$ stand for the thermal resistances between nodes 3-4 and 4-5 respectively, obtained with expression (10). Finally, $T_{4}$ and $T_{5}$ represent the temperatures of nodes 4 and 5 in the instant of time $\tau$, whereas $T^{\prime}{ }_{3}, T_{4}^{\prime}$ and $T_{5}^{\prime}$ represent the temperatures of nodes 3,4 and 5 in the instant of time $\tau+\delta \tau$. 


$$
\begin{aligned}
& \frac{T_{3}^{\prime}-T_{4}^{\prime}}{R_{34}}+\frac{T_{4}^{\prime}-T_{5}^{\prime}}{R_{45}}+\dot{Q}_{4}=\frac{C_{4}}{\delta \tau}\left(T_{4}^{\prime}-T_{4}\right) \\
& -\frac{T_{3}^{\prime}}{R_{34}}-\frac{T_{5}^{\prime}}{R_{45}}+\left(\frac{1}{R_{34}}+\frac{1}{R_{45}}+\frac{C_{4}}{\delta \tau}\right) T_{4}^{\prime}=\frac{C_{4}}{\delta \tau} T_{4}+\dot{Q}_{4} \\
& -\frac{\delta \tau}{C_{4}} \frac{1}{R_{34}} T_{3}^{\prime}-\frac{\delta \tau}{C_{4}} \frac{1}{R_{45}} T_{5}^{\prime}+\frac{\delta \tau}{C_{4}}\left(\frac{1}{R_{34}}+\frac{1}{R_{45}}+\frac{C_{4}}{\delta \tau}\right) T_{4}^{\prime}=T_{4}+\frac{\delta \tau}{C_{4}} \dot{Q}_{4} \\
& -\frac{\delta \tau}{C_{4}} \frac{1}{R_{34}} T_{3}^{\prime}+\left[\frac{\delta \tau}{C_{4}}\left(\frac{1}{R_{34}}+\frac{1}{R_{45}}\right)+1\right] T_{4}^{\prime}-\frac{\delta \tau}{C_{4}} \frac{1}{R_{45}} T_{5}^{\prime}=T_{4}+\frac{\delta \tau}{C_{4}} \dot{Q}_{4}
\end{aligned}
$$

Once conducted this process for all the nodes of a discretization, one obtains a nonlinear equation system, since the heat flow rates that emerge from the thermoelectric effects depend on the temperatures of the corresponding nodes. Then, an iterative method is proposed, which calculates temperatures for instant of time $\tau$, updates the corresponding thermal resistances and heat flow rates, and finally calculates temperatures for instant of time $\tau+\delta \tau$.

The heat exchanger attached to the cold end of the Peltier modules is composed of an aluminium dissipater and a wind tunnel. To reduce the thermal resistance of this element, a CFD modelization has been implemented using Fluent. This software provides velocity and temperature distribution in both the air and the finned dissipater. Equation (22) provides the thermal resistance of this heat exchanger.

$$
R_{d c}=\frac{T_{t e}-T_{p, c}}{\dot{q}_{p, c} S_{p}}
$$

\subsection{Design and construction of the prototypes}

The computational model described in 4.1 was used to study the performance of the hybrid refrigerator and the results were essential to select the best configuration. The 
results of this computational study are provided in section 5.1. The model indicated that configuration I was by far the worst, therefore only configurations II and III were experimentally studied.

Several prototypes featuring thermoelectric devices based on configuration II were constructed and experimentally studied, and the results were presented in a previous paper [24]. Thus, only the experimental study of configuration III is presented here, and the results are compared to those obtained previously with configuration II.

The model allowed us to study the influence of three parameters on the electric power consumptions: the number of Peltier modules, the thickness of the wall between the freezer and the thermoelectric compartment, and the thermal resistance of the heat exchangers.

Prototype 1: According to the results obtained with the computational model and several facts regarding the construction process, the first prototype of configuration III was constructed. The refrigerator selected was a Bosch-Siemens combi bottom-freezer, model KGP39331. The cooler compartment was split into two compartments, and the thermoelectric device was installed in the wall between the freezer and thermoelectric compartments. The characteristics of this prototype are displayed in Table 1, and Figure 5 shows details of the construction process. Several tests were conducted with different conditions of the fans and wind tunnels, and different voltages supplied to the fans and the Peltier modules.

Prototype 2: Subsequently, after analysing the results of the experimental tests with prototype 1, prototype 2 was designed and constructed, based on the same refrigerator model KGP39331. In this prototype, the cold side heat exchanger is composed of only one single dissipater designed according to a Fluent CFD modelization. Likewise, the hot side heat exchanger comprises also one single dissipater designed according to the results of a previous paper [30]. The characteristics of this prototype are also displayed in Table 1. 


\section{RESULTS AND ANALYSIS}

\subsection{Computational model results}

The accuracy of the model was determined by comparing simulated and experimental results obtained during the testing process of prototype 1. Figures 6 and 7 show experimental and simulated temperatures for the case when the fan over the hot side dissipater was supplied with $3.6 \mathrm{~V}$ (minimum voltage needed to make the fan rotate). Figure 6 presents the performance of the hybrid refrigerator when the Peltier modules are not supplied whereas Figure 7 shows the case when the voltage supplied to each module is $2 \mathrm{~V}$. These figures prove that the computational model predicts accurately the temperatures of all the compartments.

One fact to bear in mind is that the simulated temperatures do not follow cyclical patterns, since the model predicts effective values. In fact, the effective cooling and freezing powers are inputs of the model, which can be obtained with Eq. (23).

Effective power $(W)=$ Compressor power $(W) \times$ on/off relationship $(0 / 1)$

It is a real fact that the compressor follows an on/off pattern. Thus, once the refrigerator is switched on, the compressor works until the lower set temperature is reached. Then, it stops and the temperature rises again, so that a cyclical pattern arises. The computational model does not include this effect, but it supposes that the compressor always works at effective power.

The first computational study set out to compare the performance of configuration I and II, and quantify the differences. Procedures and electric power consumptions were published in a previous paper [24] and are summarized in Table 2, along with the results of configuration III provided by the computational model for similar working conditions, which were: ambient temperature $25^{\circ} \mathrm{C}$, cooler compartment temperature $5{ }^{\circ} \mathrm{C}$, freezer compartment temperature $-22^{\circ} \mathrm{C}$, and thermoelectric compartment temperature $0{ }^{\circ} \mathrm{C}$. Table 2 points out that configuration I is by far the worst, whereas configuration III is the most 
efficient. These results confirm the predictions raised in section 3 regarding the influence of the temperature difference between the ends of the modules on the COP of the thermoelectric device, represented by Eq. (2), which explains the significantly higher electric power consumption of the thermoelectric device in configuration I (about $100 \mathrm{~W}$ ) with respect to that of configuration III $(1.1 \mathrm{~W})$, for similar working conditions.

Then, once configuration III was proved to provide the best results regarding electric power consumption, the computational model was used again to determine the optimum values of the input variables that allow us to attain the desired constant temperature in the thermoelectric compartment, with minimum electric power consumption. Table 3 summarizes the simulated results for configuration III of the hybrid refrigerator, where one can see that the study variables are the thickness of the wall between thermoelectric and freezer compartments, thermal resistances of the heat exchangers and number of Peltier modules, whereas the constant parameters are the temperatures of the cooler compartment $\left(5^{\circ} \mathrm{C}\right)$, freezer compartment $\left(-22^{\circ} \mathrm{C}\right)$ and environment $\left(25^{\circ} \mathrm{C}\right)$.

From Table 3, one can conclude that the best results are obtained when using a 53 mm thick wall between the thermoelectric and freezer compartments, which offers a twofold benefit: less insulating material is needed and more space is available inside the thermoelectric compartment.

It is also concluded that one single Peltier module is capable of providing $-4{ }^{\circ} \mathrm{C}$ in the thermoelectric compartment. However, two Peltier modules are decided to be installed in the prototypes for two main reasons: First of all, two Peltier modules provide higher cooling power than one single module, which might be useful when a big hot mass is placed inside this compartment. Secondly, given a constant cooling power in the thermoelectric compartment, the electric power consumption of one single module is higher than the electric power consumption of two Peltier modules. This seemingly 
contradictory fact occurs owing to the fact that the COP of a Peltier module increases as the electric power supplied to it decreases, since the electric current also decreases and, in turn, the heat generated by Joule effect, as Eq. (7) indicates.

The CFD model was used to study different configurations of the dissipater attached to the cold end of the Peltier modules. The selected configuration of the cold heat exchanger for prototype 2 has top air inflow, $1.5 \times 18 \mathrm{~mm}^{2}$ fins spaced $11 \mathrm{~mm}$, and wider inflow surface.

\subsection{Experimental results}

Table 4 shows experimental temperatures and electric power consumptions of prototype 1 in steady state, for ambient temperature $20^{\circ} \mathrm{C}$, temperature of the freezer compartment $-30{ }^{\circ} \mathrm{C}$ and temperature of the cooler compartment $2{ }^{\circ} \mathrm{C}$. It must be highlighted that the thermoelectric compartment reaches $0{ }^{\circ} \mathrm{C}$ with extra electric power consumption of $0.5 \mathrm{~W}$, which comprises only the consumption of the fan, since the Peltier modules do not need to be supplied. Likewise, the thermoelectric compartment reaches -4 ${ }^{\circ} \mathrm{C}$ with an extra electric power consumption of $7.6 \mathrm{~W}$, which comprises the consumption of the fan $(0.5 \mathrm{~W})$ and the Peltier modules $(7.1 \mathrm{~W})$. Furthermore, one can observe that the temperature of the thermoelectric compartment keeps virtually constant (even though no extra temperature control system is installed) oscillating $0.6{ }^{\circ} \mathrm{C}$ at most. In contrast, temperatures at freezer and cooler compartments oscillate up to $9.3{ }^{\circ} \mathrm{C}$, as can be seen in Figures 6, 7 and 8. Moreover, the temperature in the thermoelectric compartment is easily controlled since one can modify both the voltage supplied to the modules and the voltage supplied to the fan.

Figure 8 shows temperatures at steady state of prototype 1, with $3.6 \mathrm{~V}$ supplied to the fan and $2.5 \mathrm{~V}$ supplied to the modules, which leads to $7.6 \mathrm{~W}$ of electric power 
consumption. It can be observed that the temperature difference between the cold end of the modules and the thermoelectric compartment $\left(\Delta T_{c}\right)$ is far larger than the temperature difference between the hot end of the modules and the freezer compartment $\left(\Delta T_{h}\right)$ which leads to the conclusion that the thermal resistance of the heat exchanger at the cold side is too high. This is no surprise since the heat exchanger at the cold side comprises only dissipaters whereas the heat exchanger at the hot side is composed of dissipaters, wind tunnels and fans.

In order to solve this problem, we installed a fan (no wind tunnel) inside the thermoelectric compartment to force the air to flow through the fins of the dissipater and enhance the heat transfer. Results for this small improvement of prototype 1 are shown in Table 5, where one can see the average temperatures and electric power consumptions for different working conditions of the refrigerator at constant ambient temperature of $25^{\circ} \mathrm{C}$. Results from Table 5 point out that the use of a fan in the thermoelectric compartment is highly beneficial. Specifically, the thermoelectric compartment reaches $-4{ }^{\circ} \mathrm{C}$ with $5.7 \mathrm{~W}$ of electric power consumption, for $25^{\circ} \mathrm{C}$ of ambient temperature, whereas in the previous case (when no fan was installed at the cold side) the thermoelectric compartment reached $4{ }^{\circ} \mathrm{C}$ with $7.5 \mathrm{~W}$ of electric consumption, even though the ambient temperature was $20{ }^{\circ} \mathrm{C}$.

One can also realize that the temperature in the freezer compartment has strong influence on the electric power consumption of the modules. For instance, for electric power consumption of $5.5 \mathrm{~W}$, the temperature in the thermoelectric compartment reaches $4{ }^{\circ} \mathrm{C}$ if the temperature in the freezer compartment is $-29^{\circ} \mathrm{C}$. However, the temperature in the thermoelectric compartment reaches $-3{ }^{\circ} \mathrm{C}$ if the temperature in the freezer compartment is $-24{ }^{\circ} \mathrm{C}$. The reason why this occurs is that, as the temperature at the freezer compartment decreases, the temperature difference between the ends of the modules also decreases, which leads to an increase in the COP of the modules. 
These experimental results, along with CFD simulations for the dissipater and the wind tunnel in the thermoelectric compartment, led to the construction of a new prototype of hybrid refrigerator for configuration III, called prototype 2, shown in Figure 9. Table 6 shows that the temperature in the thermoelectric compartment of this prototype 2 keeps constant at $0.4{ }^{\circ} \mathrm{C}$, oscillating $\pm 0.2^{\circ} \mathrm{C}$ at most, with $1.1 \mathrm{~W}$ of electric power consumption of the thermoelectric device, for ambient temperature $25^{\circ} \mathrm{C}$, temperature in the cooler compartment set at $5{ }^{\circ} \mathrm{C}$ and temperature in the freezer compartment set at $-22{ }^{\circ} \mathrm{C}$. This electric power consumption includes only the fans, since there is no need to supply the modules. The electric power consumption of the hybrid refrigerator was $46.3 \mathrm{~W}$ (1.11 $\mathrm{kWh}$ /day). Likewise, for the same temperature conditions, the temperature in the thermoelectric compartment was $-4.1{ }^{\circ} \mathrm{C}$, with $1.8 \mathrm{~W}$ of electric power consumption of the thermoelectric device, and $49.2 \mathrm{~W}(1.18 \mathrm{kWh} /$ day $)$ of electric power consumption of the hybrid refrigerator.

These facts embody the significant improvement achieved with prototype 2 . Specifically, the electric power consumption of the thermoelectric device decreases with respect to that attained previously with prototypes of configuration II [24] from 4.9 to 1.1 $\mathrm{W}$, which leads to a reduction by about $8 \%$ of the electric power consumption of the hybrid refrigerator. This means that this refrigerator can be included in energy efficiency class A, according European rules and regulations [31].

This technology presents a huge potential since the quality of food conservation increases via improving the temperature control system, with competitive values of electric power consumption. What is more, the thermoelectric device is also an efficient system to remove the ice built up in the dissipater of the thermoelectric compartment. In fact, if the voltage supplied to the Peltier modules is reversed, the thermoelectric device works as a heat pump and, therefore, the dissipater warms up and the ice melts. 


\section{CONCLUSIONS}

This paper presents a hybrid refrigerator that combines thermoelectrics and vapour compression technology, which has an extra compartment whose temperature can be adjusted at any value between 0 and $-4{ }^{\circ} \mathrm{C}$, oscillating $0.4{ }^{\circ} \mathrm{C}$ at most. This new compartment is controlled by a thermoelectric device that provides high quality temperature control, and eliminates the cyclical behaviour of devices refrigerated by vapour compression systems, which is beneficial to the conservation of food.

The design and optimization of this hybrid refrigerator were based on a computational model designed for this application. The final design of the thermoelectric device comprises two Peltier modules and one dissipater at either end of the modules, endowed with a fan and a wind tunnel. Among all configurations studied, model simulations suggest that the thermoelectric device must be installed in the wall between the thermoelectric and the freezer compartments, so that the heat generated at the hot end of the modules is given off into the freezer compartment, that is, configuration III.

Experimental results with the improved prototype of configuration III indicate that the temperature in the thermoelectric compartment keeps constant at $0{ }^{\circ} \mathrm{C}$ and oscillates 0.4 ${ }^{\circ} \mathrm{C}$ at most, with $1.1 \mathrm{~W}$ of electric power consumption of the thermoelectric device, for ambient temperature $25^{\circ} \mathrm{C}$, temperature in the cooler compartment $5^{\circ} \mathrm{C}$ and temperature in the freezer compartment $-22{ }^{\circ} \mathrm{C}$. In these conditions, the electric power consumption of the refrigerator is $46.3 \mathrm{~W}(1.11 \mathrm{kWh} /$ day $)$. Likewise, for the same temperature conditions, the temperature in the thermoelectric compartment is $-4.1{ }^{\circ} \mathrm{C}$, with $1.8 \mathrm{~W}$ of electric power consumption of the thermoelectric device, and $49.2 \mathrm{~W}(1.18 \mathrm{kWh} /$ day $)$ of electric power consumption of the refrigerator. These results indicate that the electric power consumption of the best prototype of configuration III is $10 \%$ lower than that attained with the best prototype of configuration II, which emits the heat generated at the hot side of the Peltier modules to the cooling compartment. 
These facts prove that the combination of vapour compression and thermoelectrics is an attractive alternative to current domestic refrigerators, given the competitive values of electric power consumption of hybrid refrigerators. Specifically, the hybrid refrigerator presented in this paper is included in energy efficiency class A, according European rules and regulations.

\section{ACKNOWLEDGEMENTS}

The authors are indebted to Bosch-Siemens enterprise for the economic support to this work, whose results are been protected under patent [26].

\section{REFERENCES}

[1] D.M. Rowe, Thermoelectrics handbook macro to nano, first ed., CRC Press, Boca Raton, FL, 2006.

[2] A.F. Ioffe, Semiconductor thermoelements and thermoelectric cooling, Infosearch, London, UK, 1957.

[3] M.S. Crouthamel, J.F. Panas, B. Shelpuk, Nine ton thermoelectric air-conditioning system, ASHRAE Tran. 70 (1964) 139-148.

[4] D. Jones, B. Mathiprakasam, P. Heenan, D. Brantley, Development of $1000 \mathrm{~W}$ thermoelectric air-conditioner, 13th International Conference on Thermoelectric Energy Conversion, Nancy, France, 1989, pp. 232-234.

[5] Marlow Industries, www.marlow.com, 2011.

[6] Global Medical Instrumentation, www.gmi-inc.com, 2011.

[7] J.G. Vián, D. Astrain, M. Domínguez, Numerical modelling and design of a thermoelectric dehumidifier. Appl. Therm. Eng. 22 (2002) 407-422.

[8] L.E. Bell, Cooling, heating, generating power, and recovering waste heat with thermoelectric systems, Science 321 (2008) 1457-1461. 
[9] G. Min, D.M. Rowe, Experimental evaluation of prototype thermoelectric domesticrefrigerators, Appl. Energ. 83 (2006) 133-152.

[10] G. Min, D.M. Rowe, Cooling performance of integrated thermoelectric microcooler, Solid State Electron. 43 (1999) 923-929.

[11] J.M. Gordon, K.C. Ng, H.T. Chua, A. Chakraborty, The electro-adsorption chiller: a miniaturized cooling cycle with applications to micro-electronics, Int. J. Refrig. 25 (2002) 1025-1033.

[12] S.B. Riffat, M.A. Xiaoli, R. Wilson, Performance simulation and experimental testing of a novel thermoelectric heat pump system, Appl. Therm. Eng. 26 (2006) 494-501.

[13] Y. Chang, C. Chang, M. Ke, S. Chen, Thermoelectric air-cooling module for electronic devices, Appl. Therm. Eng. 29 (2009) 2731-2737.

[14] R. Chein, G. Huang, Thermoelectric cooler application in electronic cooling, Appl. Therm. Eng. 24 (2004) 2207-2217.

[15] H. Mao-Gang, L. Tie-Chen, L. Zhi-Gang, Z. Ying, Testing of the mixing refrigerants HFC152a/HFC125 in a domestic refrigerator, Appl. Therm. Eng. 25 (2005) 11691181 .

[16] D. Reid, Food preservation, ASHRAE J. 41 (1999) 40-45.

[17] L. Buzelin, S. Amico, J. Vargas, J. Parise, Experimental development of an intelligent refrigeration system, Int. J. Refrig. 28 (2005) 165-175.

[18] D.Y. Liu, W.R. Chang, J.Y. Lin, Performance comparison with effect of door opening on variable and fixed frequency refrigerators/freezers, Appl. Therm. Eng. 24 (2004) 2281-2292.

[19] Z. Lu, G. Ding, Temperature and time-sharing running combination control strategy of two-circuit cycle refrigerator freezer with parallel evaporators, Appl. Therm. Eng. 26 (2006) 1208-1217.

[20]A. Leva, L. Piroddi, M. Di Felice, A. Boer, R. Paganini, Adaptive relay-based control of household freezers with on-off actuators, Control Eng. Pract. 18 (2010) 94-102. 
[21]P. Mithraratne, N.E. Wijeysundera, An experimental and numerical study of hunting in thermostatic-expansion-valve-controlled evaporators, Int. J. Refrig. 25 (2002) 992998.

[22] V. Mulay, A. Kulkarni, D. Agonafer, R. Schmidt, Effect of the location and the properties of thermostatic expansion valve sensor bulb on the stability of a refrigeration system, J. Heat Transf. 127 (2005) 85-94.

[23] J.G. Vián, D. Astrain, Development of a thermoelectric refrigerator with two-phase thermosyphons and capillary lift. Appl. Therm. Eng. 29 (2009) 1935-1940.

[24] J.G. Vián, D. Astrain, Development of a hybrid refrigerator combining thermoelectricity and vapour-compression technologies. Appl. Therm. Eng. 29 (2009) 3319-3327.

[25] D. Astrain, J.G. Vián, M. Domínguez, Increase of COP in the thermoelectric refrigeration by the optimisation of heat dissipation, Appl. Therm. Eng. 23 (2003) 2183-2200.

[26] D. Astrain, J.G. Vián, J. Calvillo, J. Alemán, S. García, Refrigerator device and process in order to keep constant the inner temperature in a compartment of a domestic refrigerator, FEK / Petitioner: BSH ELECTRODOMESTICOS ESPAÑA, S.A. Applications number: P200701914 / Application date: 29/06/2007 NumZTG: 2007P01673ES.

[27] M.N. Ozisik, Finite difference methods in heat transfer, first ed., CRC Press Boca Raton, FL, 1994.

[28] G.V. Parmelee, R.G. Huebscher, Heat transfer by forced convection along a smooth flat surface, Heat Piping Air. Cond. 19 (1947) 115-130.

[29] T.M. Ritzer, P.G. Lau, Economic optimization of heat sink, 13th International Conference on Thermoelectrics, Kansas City, Missouri, USA, 1994, pp. 177-180.

[30] D. Astrain, J.G. Vián, Study and optimization of the heat dissipater of a thermoelectric refrigerator, J. Enhanc. Heat Transf. 12 (2005) 159-170.

[31] UNE-EN 1532006 and 94/2/CE. 


\section{FIGURE CAPTIONS}

Figure 1. Configurations of the thermoelectric device in the hybrid refrigerator.

Figure 2. Discretization of the hybrid refrigerator for configuration I.

Figure 3. Discretization of the hybrid refrigerator for configuration II.

Figure 4. Discretization of the hybrid refrigerator for configuration III.

Figure 5. Pictures of the construction process of prototype 1.

Figure 6. Simulated and experimental temperatures of prototype 1, with no voltage supplied to the Peltier modules.

Figure 7. Simulated and experimental temperatures of prototype 1, with $2 \mathrm{~V}$ supplied to either Peltier module.

Figure 8. Experimental temperatures of prototype 1, with $2.5 \mathrm{~V}$ supplied to the Peltier modules.

Figure 9. Front picture of prototype 2. 


\section{TABLES}

\begin{tabular}{|c|c|c|}
\hline & Prototype 1 & Prototype 2 \\
\hline Volume freezer compartment & $84 \times 10^{-3} \mathrm{~m}^{3}$ & $84 \times 10^{-3} \mathrm{~m}^{3}$ \\
\hline Volume cooler compartment & $184 \times 10^{-3} \mathrm{~m}^{3}$ & $184 \times 10^{-3} \mathrm{~m}^{3}$ \\
\hline Volume thermoelectric compartment & $71 \times 10^{-3} \mathrm{~m}^{3}$ & $71 \times 10^{-3} \mathrm{~m}^{3}$ \\
\hline Number of Peltier modules & 2 Marlow DT12-6L & 2 Marlow DT12-6L \\
\hline Cold side heat exchanger & $\begin{array}{l}\text { Two } 120 \times 120 \times 12 \mathrm{~mm}^{3} \\
\text { dissipaters }\end{array}$ & $\begin{array}{l}\text { One } 150 \times 180 \times 12 \mathrm{~mm}^{3} \\
\text { dissipater, with } \\
\text { fins separated } 11 \mathrm{~mm} \\
\text { One fan SUNON } \\
\text { KDE1212PTB1-6A }\end{array}$ \\
\hline Hot side heat exchanger & $\begin{array}{l}\text { Two } 120 \times 120 \times 12 \mathrm{~mm}^{3} \\
\text { dissipaters, with fins } \\
\text { separated } 5.5 \mathrm{~mm} \\
\text { Two fans SUNON } \\
\text { KDE1212PTB1-6A }\end{array}$ & $\begin{array}{l}\text { One } 150 \times 180 \times 12 \mathrm{~mm}^{3} \\
\text { dissipater with fins } \\
\text { separated } 5.5 \mathrm{~mm} \\
\text { One fan SUNON } \\
\text { KDE1212PTB1-6A }\end{array}$ \\
\hline
\end{tabular}

Table 1. Characteristics of the prototypes of configuration III.

\begin{tabular}{|l|c|c|c|}
\hline & Configuration I & Configuration II & Configuration III \\
\hline$\dot{W}_{\text {freez }}[\mathrm{W}]$ & 25.2 & 25.3 & 30.6 \\
\hline$\dot{W}_{\text {cool }}[\mathrm{W}]$ & 13.8 & 19.7 & 13.5 \\
\hline$\dot{W}_{\text {te }}[\mathrm{W}]$ & 99.6 & 4.9 & 1.1 \\
\hline$\dot{W}_{\text {tot }}[\mathrm{W}]$ & 138.6 & 49.9 & 45.2 \\
\hline Energy efficiency class & No classifiable & $\mathrm{B}$ & $\mathrm{A}$ \\
\hline
\end{tabular}

Table 2. Simulated electric power consumption for configurations I, II and III. 


\begin{tabular}{|c|c|c|c|c||c|c|c|c|c|}
\hline \begin{tabular}{c}
$e_{\text {te-freez }}(\mathrm{mm})$ \\
\hline 73
\end{tabular} & $\begin{array}{c}\text { Number } \\
\text { Peltier }\end{array}$ & $\begin{array}{c}R_{d h} \\
(K / W)\end{array}$ & $\begin{array}{c}R_{d c} \\
(K / W)\end{array}$ & $\begin{array}{c}V_{t e} \\
(V)\end{array}$ & $\begin{array}{c}T_{\text {te }} \\
\left({ }^{\circ} \mathrm{C}\right)\end{array}$ & $\begin{array}{c}\dot{W}_{\text {te }} \\
(W)\end{array}$ & $\begin{array}{c}\dot{W}_{\text {freez }} \\
(W)\end{array}$ & $\begin{array}{c}\dot{W}_{\text {cool }} \\
(W)\end{array}$ & $\begin{array}{c}\dot{W}_{\text {tot }} \\
(W)\end{array}$ \\
\hline \hline 73 & 2 & 0.3 & 3.37 & 0 & 7.9 & 2 & 29.1 & 16.4 & 47.5 \\
\hline 73 & 2 & 1 & 3.37 & 0 & 2.9 & 0 & 30.9 & 16.2 & 47.1 \\
\hline 64 & 2 & 1 & 3.37 & 0 & 2.6 & 0 & 30.9 & 16.2 & 47.1 \\
\hline 53 & 1 & 0.3 & 0.8 & 0 & 1.2 & 4 & 31.2 & 16.1 & 51.3 \\
\hline 53 & 1 & 0.3 & 0.8 & 1.2 & -4 & 4.8 & 33.5 & 15.7 & 54 \\
\hline 53 & 1 & 1 & 3.37 & 0 & 7.9 & 0 & 28.8 & 16.4 & 45.2 \\
\hline 53 & 2 & 0.3 & 0.8 & 0 & -5.6 & 4 & 33.6 & 15.6 & 53.2 \\
\hline 53 & 2 & 0.3 & 3.37 & 1.2 & -4 & 3.7 & 35 & 15.7 & 54.4 \\
\hline 53 & 2 & 1 & 3.37 & 0 & 2.1 & 0 & 30.1 & 16.1 & 46.2 \\
\hline 53 & 2 & 1 & 3.37 & 2.1 & -4 & 5.1 & 39.9 & 15.7 & 60.7 \\
\hline
\end{tabular}

Table 3. Simulated results of configuration III.

\begin{tabular}{|c|c|c|c|c|c|c|c|c|c|c|}
\hline \multirow{2}{*}{\multicolumn{2}{|c|}{ Voltage }} & \multicolumn{9}{|c|}{ Results } \\
\hline & & \multicolumn{2}{|c|}{ Freezer } & \multicolumn{2}{|c|}{ Cooler } & \multicolumn{2}{|c|}{ Thermoelectric } & \multicolumn{3}{|c|}{ Electric consumption } \\
\hline $\begin{array}{c}\text { Fan at } \\
\text { Freezer } \\
\text { [V] }\end{array}$ & $\begin{array}{c}\text { Modules } \\
{[\mathrm{V}]}\end{array}$ & $\begin{array}{c}\Delta \mathrm{T}_{\text {freez }} \\
{\left[{ }^{\circ} \mathrm{C}\right]}\end{array}$ & $\begin{array}{c}\mathrm{T}_{\text {freez }} \\
\text { average } \\
{\left[{ }^{\circ} \mathrm{C}\right]}\end{array}$ & $\begin{array}{c}\Delta \mathbf{T}_{\text {cool }} \\
{\left[{ }^{\circ} \mathrm{C}\right]}\end{array}$ & $\begin{array}{c}\mathbf{T}_{\text {cool }} \\
\text { average } \\
{\left[{ }^{\circ} \mathrm{C}\right]}\end{array}$ & $\begin{array}{l}\Delta \mathbf{T}_{\mathrm{te}} \\
{\left[{ }^{\circ} \mathrm{C}\right]}\end{array}$ & $\begin{array}{c}\mathbf{T}_{\text {te average }} \\
{\left[{ }^{\circ} \mathrm{C}\right]}\end{array}$ & $\begin{array}{c}\text { Fan at } \\
\text { Freezer } \\
{[\mathrm{W}]}\end{array}$ & $\begin{array}{c}\text { Modules } \\
{[\mathrm{W}]}\end{array}$ & $\begin{array}{c}\text { Total } \\
{[\mathrm{W}]}\end{array}$ \\
\hline 3.6 & 0 & 6.0 & -31.9 & 8.4 & 1.1 & 0.5 & -0.1 & 0.54 & 0.00 & 0.54 \\
\hline 0 & 0 & 8.2 & -32.0 & 9.3 & 0.2 & 0.4 & 7.1 & 0.00 & 0.00 & 0.00 \\
\hline 3.6 & 1 & 5.8 & -31.8 & 8.5 & 1.2 & 0.6 & -2.6 & 0.54 & 1.48 & 2.02 \\
\hline 3.6 & 0.5 & 5.9 & -31.8 & 8.6 & 1.2 & 0.5 & -2.0 & 0.54 & 0.42 & 0.96 \\
\hline 3.6 & 1.5 & 5.8 & -31.8 & 8.5 & 1.0 & 0.6 & -3.3 & 0.54 & 2.57 & 3.11 \\
\hline 3.6 & 2 & 5.4 & -31.9 & 8.5 & 1.1 & 0.6 & -3.8 & 0.50 & 4.60 & 5.10 \\
\hline 3.6 & 2.5 & 5.2 & -32.0 & 8.5 & 1.1 & 0.6 & -3.9 & 0.50 & 7.08 & 7.58 \\
\hline
\end{tabular}

Table 4. Experimental results with prototype 1. 


\begin{tabular}{|c|c|c|c|c|c|c|c|c|c|c|c|c|c|}
\hline \multirow[b]{2}{*}{$\begin{array}{l}V_{t e} \\
{[V]} \\
\end{array}$} & \multirow[b]{2}{*}{$\begin{array}{c}\mathrm{T}_{\mathrm{a}} \\
{\left[{ }^{\circ} \mathrm{C}\right]}\end{array}$} & \multirow[b]{2}{*}{$\begin{array}{l}\mathrm{T}_{\text {freez }} \\
{\left[{ }^{\circ} \mathrm{C}\right]}\end{array}$} & \multirow[b]{2}{*}{$\begin{array}{l}T_{\text {cool }} \\
{\left[{ }^{\circ} \mathrm{C}\right]} \\
\end{array}$} & \multicolumn{2}{|c|}{ Freezer } & \multicolumn{2}{|c|}{ Cooler } & \multicolumn{2}{|c|}{ Thermoelectric } & \multicolumn{4}{|c|}{ Electric consumption [W] } \\
\hline & & & & $\begin{array}{c}T_{\text {freez }} \\
\text { average } \\
{\left[{ }^{\circ} \mathrm{C}\right]}\end{array}$ & $\begin{array}{c}\Delta \mathrm{T}_{\text {freez }} \\
{\left[{ }^{\circ} \mathrm{C}\right]}\end{array}$ & $\begin{array}{c}\mathbf{T}_{\text {cool }} \\
\text { average } \\
{\left[{ }^{\circ} \mathrm{C}\right]}\end{array}$ & $\begin{array}{c}\Delta \mathbf{T}_{\text {cool }} \\
{\left[{ }^{\circ} \mathrm{C}\right]}\end{array}$ & $\begin{array}{c}\mathrm{T}_{\text {te }} \\
\text { average } \\
{\left[{ }^{\circ} \mathrm{C}\right]}\end{array}$ & $\begin{array}{l}\Delta \mathrm{T}_{\text {te }} \\
\left.{ }^{\mathrm{o}} \mathrm{C}\right]\end{array}$ & $\begin{array}{c}\text { Fan } \\
\text { Freezer }\end{array}$ & $\begin{array}{c}\text { Fan } \\
\text { Cooler }\end{array}$ & Modules & Total \\
\hline 0 & 25 & -22 & 6 & -28.5 & 7.6 & 5 & 4.7 & 3.1 & 0.5 & 0.8 & 0.0 & 0.0 & 0.8 \\
\hline 1 & 25 & -22 & 6 & -28.3 & 7.4 & 4.9 & 4 & 1.4 & 0.5 & 0.8 & 0.0 & 1.2 & 2.0 \\
\hline 2 & 25 & -22 & 6 & -28.1 & 7.5 & 5 & 6.1 & 0.1 & 0.4 & 0.8 & 0.0 & 4.4 & 5.2 \\
\hline 0 & 25 & -22 & 6 & -30.8 & 5.6 & 4.9 & 6.5 & -1.3 & 0.8 & 0.8 & 0.3 & 0.0 & 1.1 \\
\hline 1 & 25 & -22 & 6 & -30.7 & 5.4 & 4.9 & 4.2 & -3.1 & 0.7 & 0.8 & 0.3 & 1.4 & 2.5 \\
\hline 2 & 25 & -22 & 6 & -28 & 7.3 & 4.8 & 3.7 & -4.6 & 1 & 0.8 & 0.3 & 4.6 & 5.7 \\
\hline 0 & 25 & -26 & 6 & -29.6 & 4.5 & 5 & 4 & -2.5 & 9 & 1.8 & 0.3 & 0.0 & 2.1 \\
\hline 2 & 25 & -26 & 6 & -29.9 & 0.4 & 4.9 & 3.6 & -7.5 & 0.7 & 1.7 & 0.3 & 4.6 & 6.7 \\
\hline 0 & 25 & -18 & 6 & -23.8 & 9.2 & 5 & 5.8 & 0.9 & 0.7 & 0.8 & 0.3 & 0.0 & 1.1 \\
\hline 1 & 25 & -18 & 6 & -23.8 & 9 & 4.9 & 3.7 & -1.6 & 0.9 & 0.8 & 0.3 & 1.2 & 2.3 \\
\hline 2 & 25 & -18 & 6 & -23.8 & 9.2 & 4.9 & 5.1 & -3 & 1 & 0.8 & 0.3 & 4.4 & 5.5 \\
\hline
\end{tabular}

Table 5. Experimental results of prototype 1 (ambient temperature $25^{\circ} \mathrm{C}$ ).

\begin{tabular}{|c|c|c|c|c|c|c|c|c|c|c|c|c|c|}
\hline \multirow[b]{2}{*}{$\begin{array}{l}\mathrm{V}_{\mathrm{te}} \\
{[\mathrm{V}]}\end{array}$} & \multirow[b]{2}{*}{$\begin{array}{l}\mathrm{T}_{\mathrm{a}} \\
{[\stackrel{0}{ } \mathrm{C}]}\end{array}$} & \multirow[b]{2}{*}{$\begin{array}{c}T_{\text {freez }} \\
{\left[{ }^{\circ} \mathrm{C}\right]} \\
\end{array}$} & \multirow[b]{2}{*}{$\begin{array}{l}T_{\text {cool }} \\
{\left[{ }^{\circ} \mathrm{C}\right]}\end{array}$} & \multicolumn{2}{|c|}{ Freezer } & \multicolumn{2}{|c|}{ Cooler } & \multicolumn{2}{|c|}{ Thermoelectric } & \multicolumn{4}{|c|}{ Electric consumption [W] } \\
\hline & & & & $\begin{array}{c}\mathrm{T}_{\text {freez }} \\
\text { average } \\
{\left[{ }^{\circ} \mathrm{C}\right]}\end{array}$ & $\begin{array}{c}\Delta \mathrm{T}_{\text {freez }} \\
{\left[{ }^{\circ} \mathrm{C}\right]}\end{array}$ & $\begin{array}{c}\mathbf{T}_{\text {cool }} \\
\text { average } \\
{\left[{ }^{\circ} \mathrm{C}\right]}\end{array}$ & $\begin{array}{c}\Delta \mathrm{T}_{\text {cool }} \\
{\left[{ }^{\circ} \mathrm{C}\right]}\end{array}$ & $\begin{array}{c}\mathrm{T}_{\text {te }} \\
\text { average } \\
{\left[{ }^{\circ} \mathrm{C}\right]}\end{array}$ & $\begin{array}{l}\Delta \mathrm{T}_{\mathrm{te}} \\
{\left[{ }^{\circ} \mathrm{C}\right]}\end{array}$ & $\begin{array}{c}\text { Fan } \\
\text { Freezer }\end{array}$ & $\begin{array}{c}\text { Fan } \\
\text { Cooler }\end{array}$ & Modules & Total \\
\hline 0 & 25 & -22 & 5 & -28.8 & 9 & 7.1 & 6 & 0.4 & 0.4 & 0.93 & 0.18 & 0 & 46.3 \\
\hline 0.55 & 25 & -22 & 5 & -28.7 & 9 & 7.4 & 6 & -4.1 & 0.4 & 1 & 0.42 & 0.4 & 49.2 \\
\hline 0 & 25 & -18 & 5 & -25.1 & 10 & 7.3 & 6 & -0.2 & 0.4 & 1 & 0.53 & 0 & 42.5 \\
\hline
\end{tabular}

Table 6. Experimental results of prototype 2. 


\section{FIGURES}

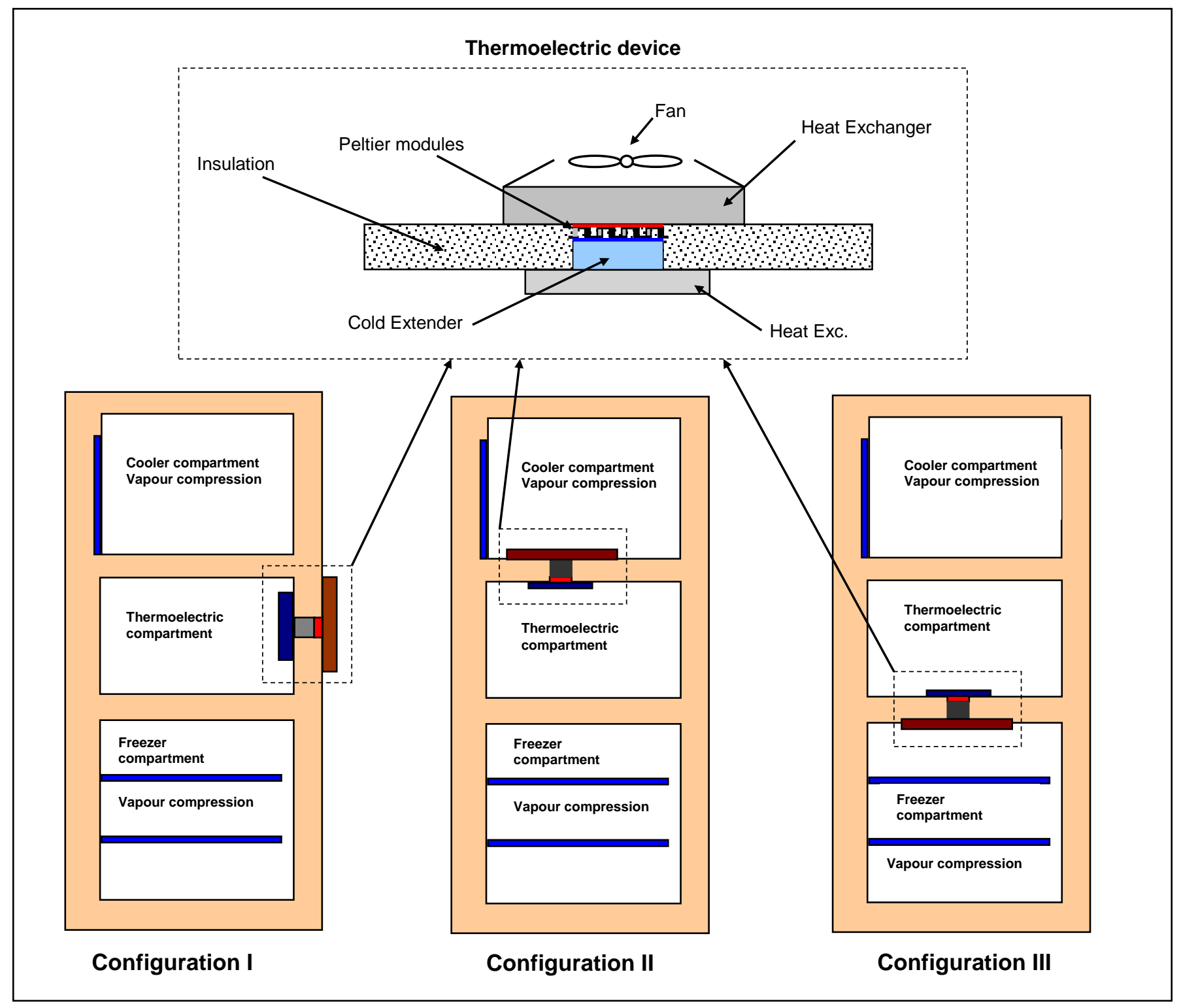

Figure 1. Configurations of the thermoelectric device in the hybrid refrigerator. 


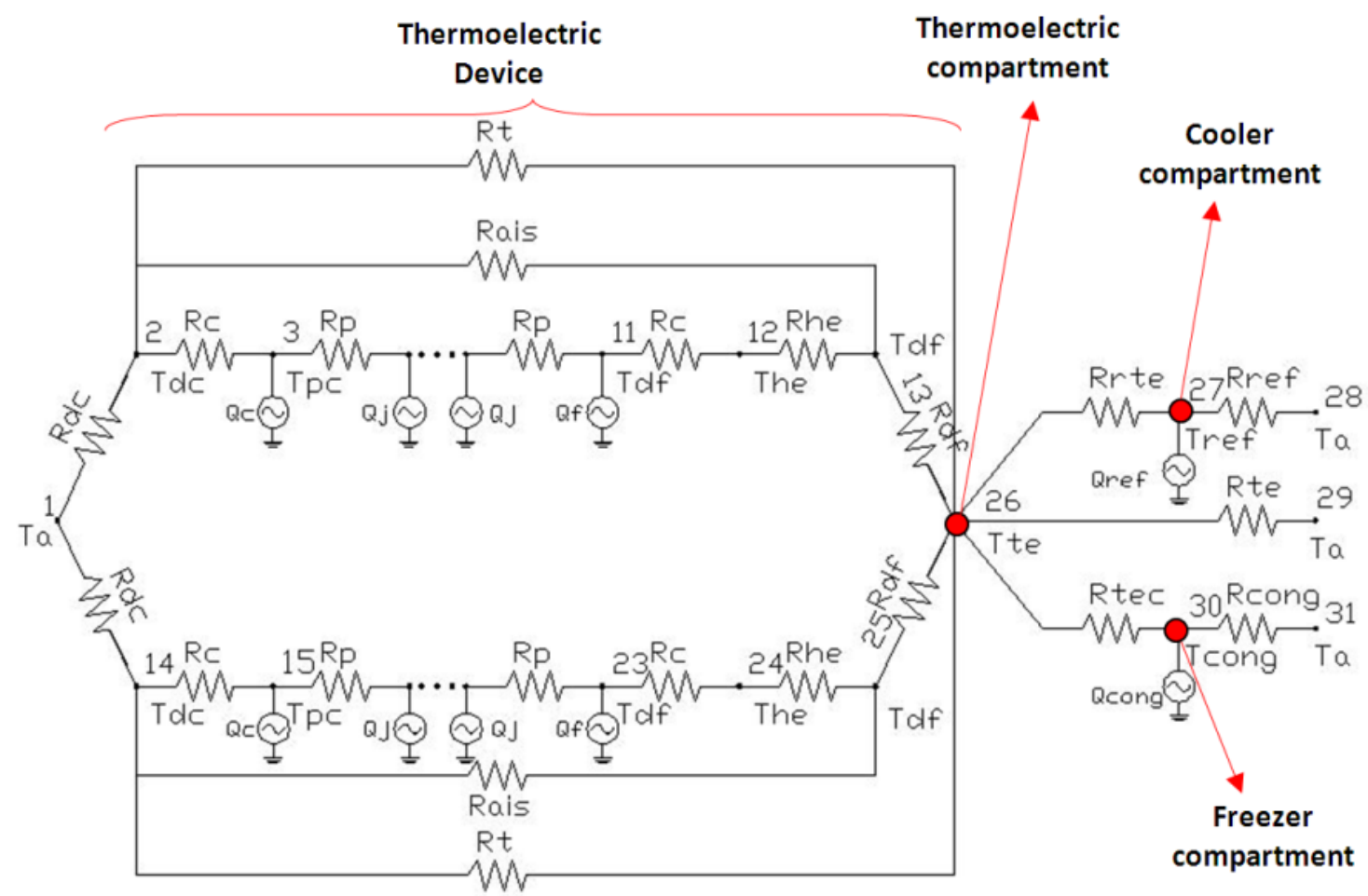

Figure 2. Discretization of the hybrid refrigerator for configuration I.

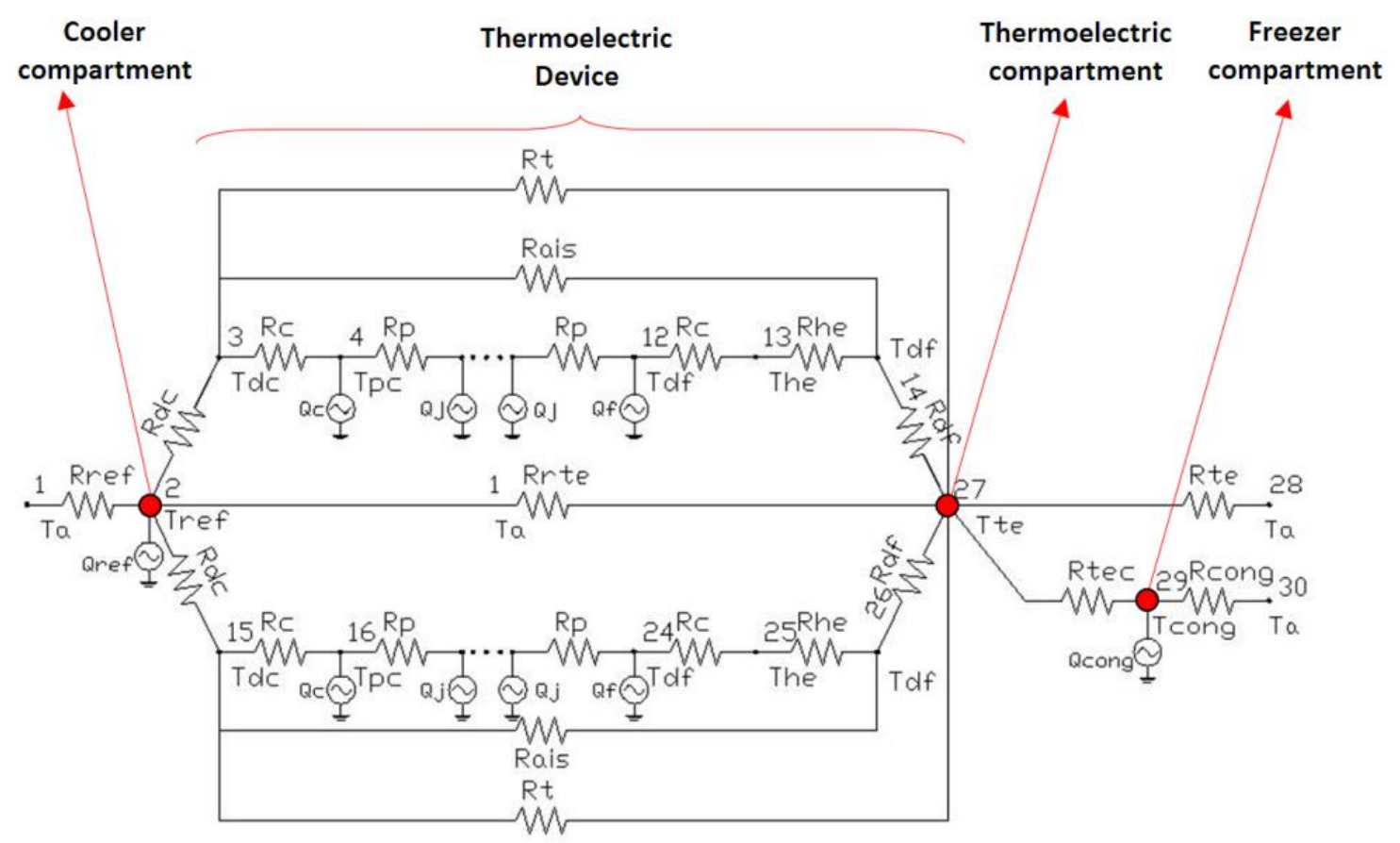

Figure 3. Discretization of the hybrid refrigerator for configuration II. 


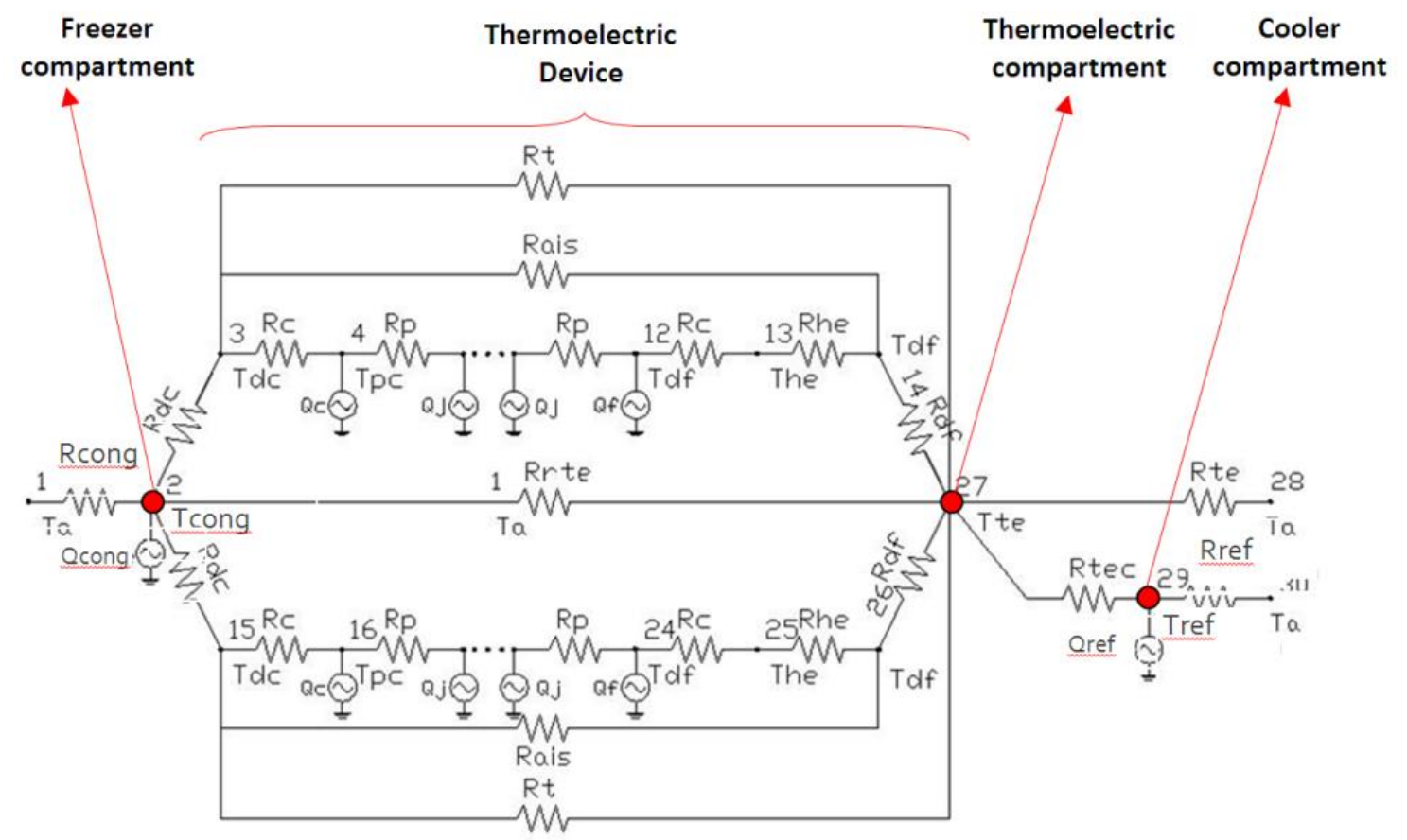

Figure 4. Discretization of the hybrid refrigerator for configuration III.
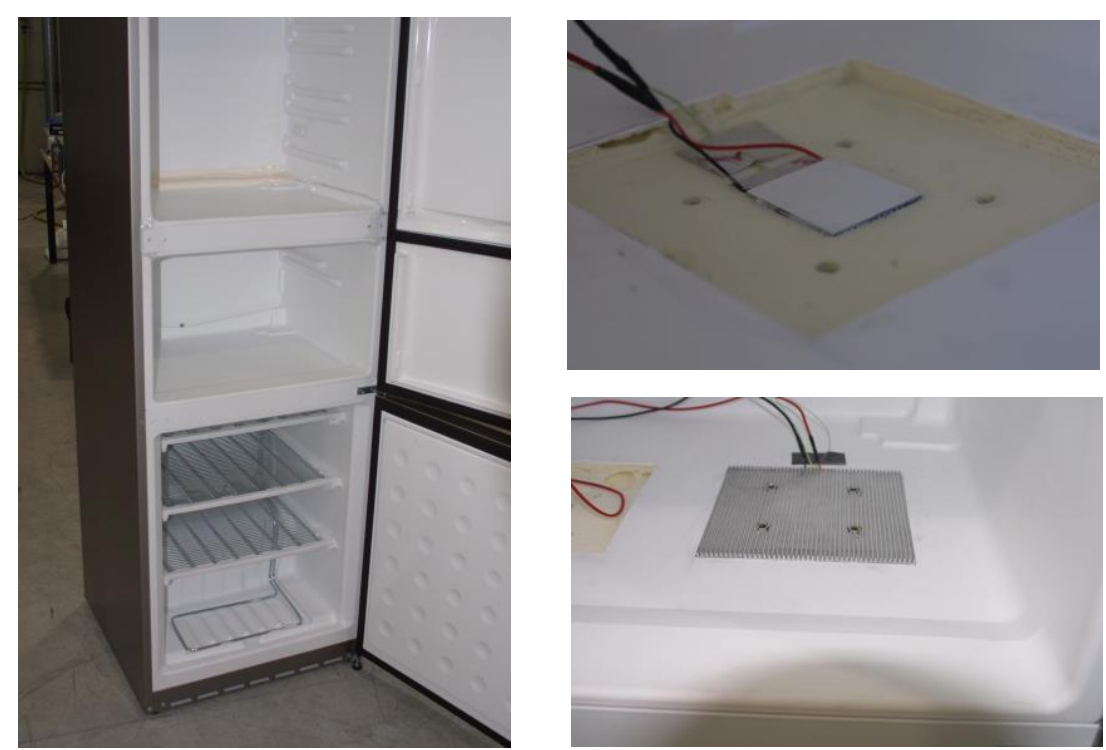

Figure 5. Pictures of the construction process of prototype 1. 


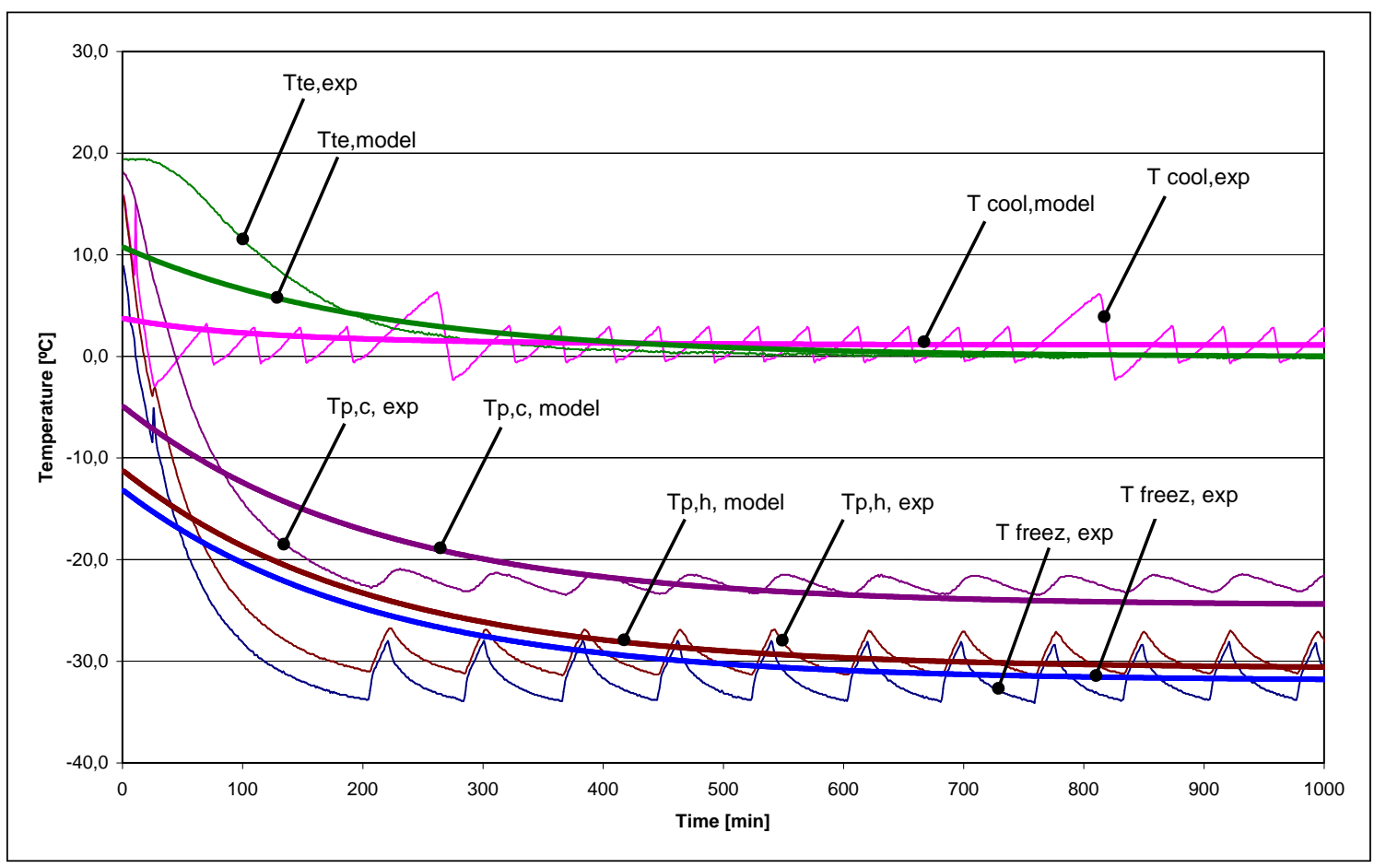

Figure 6. Simulated and experimental temperatures of prototype 1, with no voltage supplied to the Peltier modules.

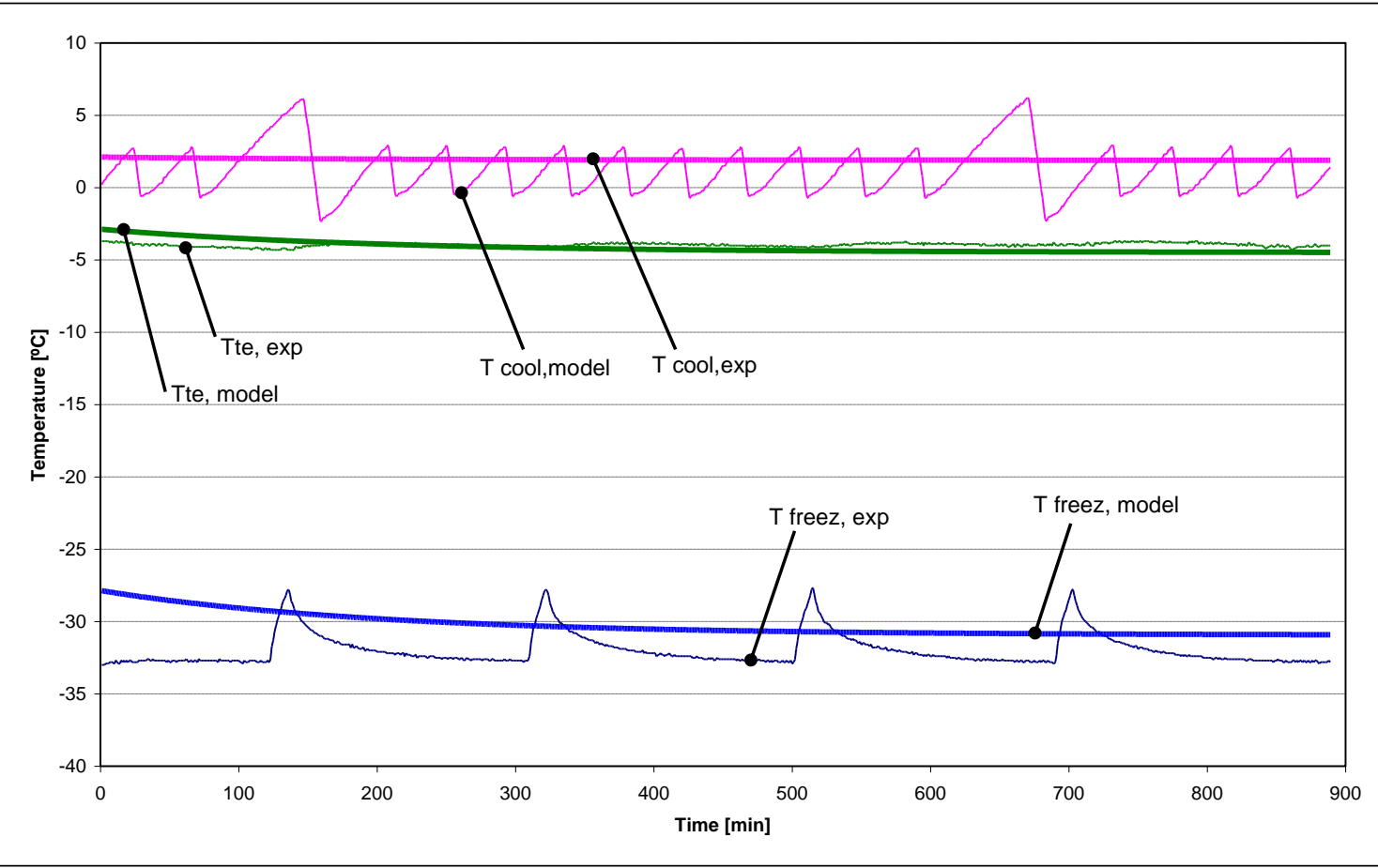

Figure 7. Simulated and experimental temperatures of prototype 1, with $2 \mathrm{~V}$ supplied to either Peltier module. 


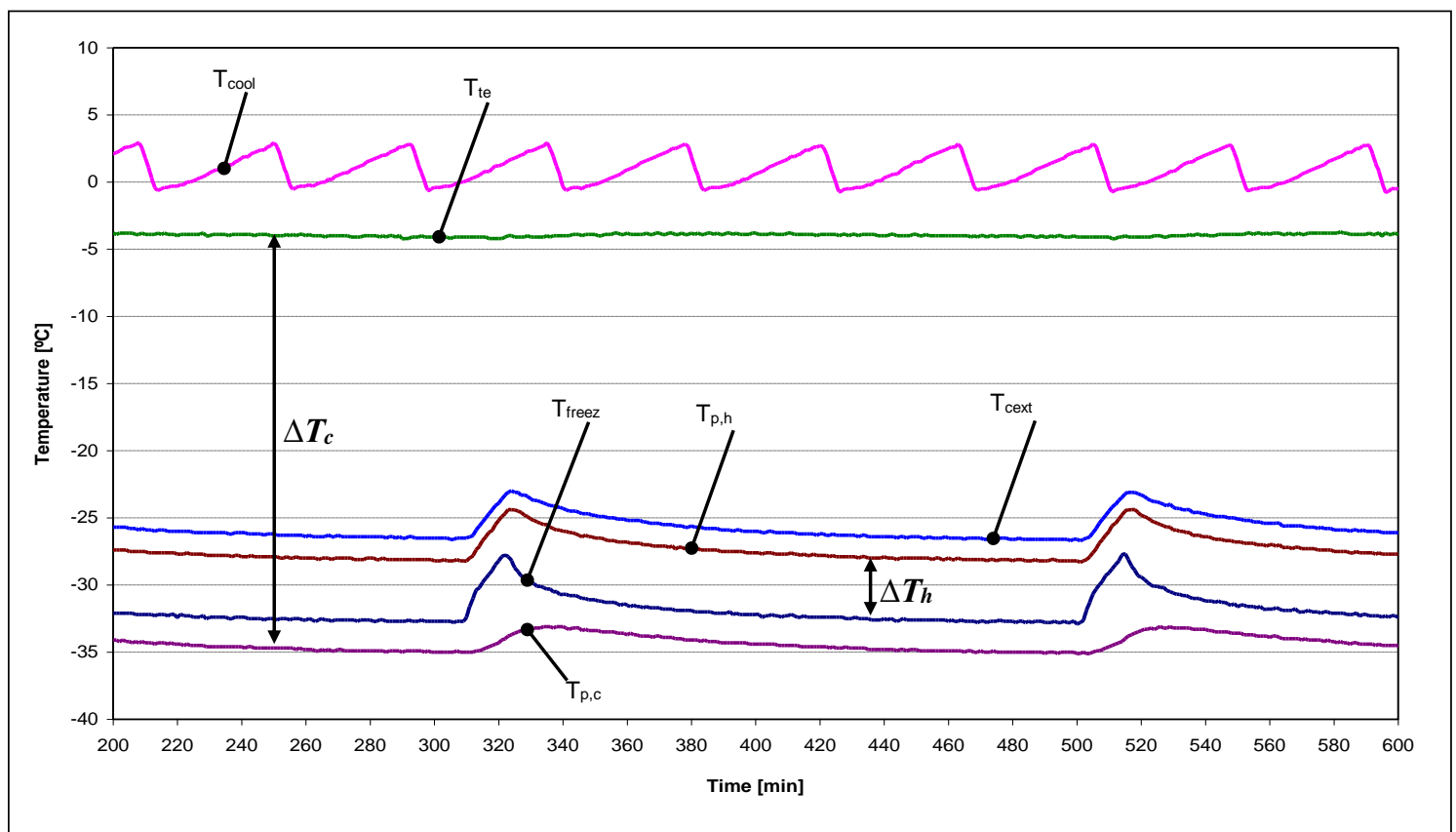

Figure 8. Experimental temperatures of prototype 1, with $2.5 \mathrm{~V}$ supplied to the Peltier modules.

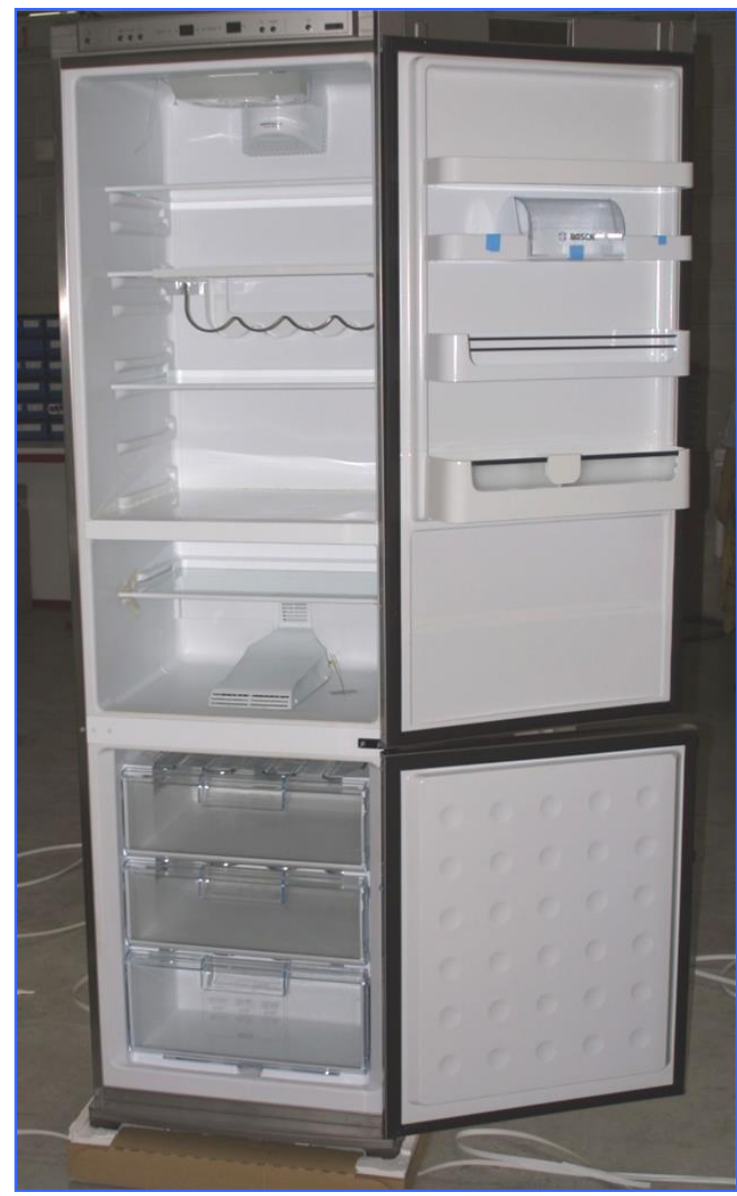

Figure 9. Front picture of prototype 2 . 